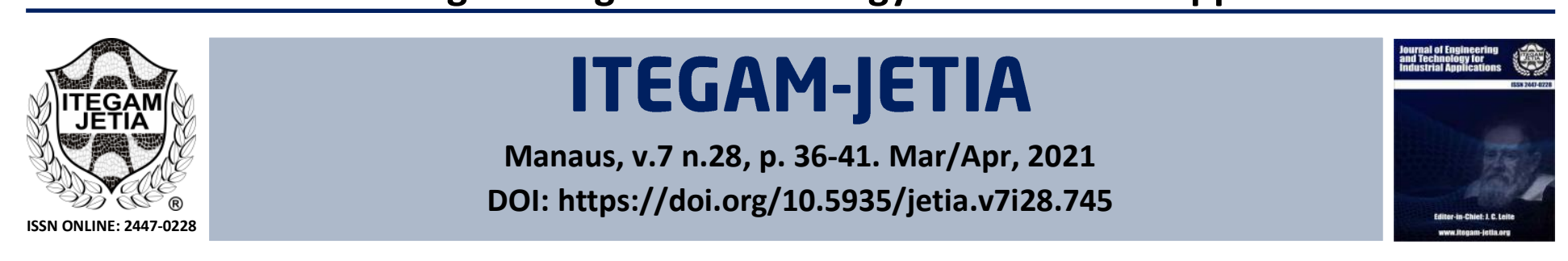

\title{
MODELING A CLOSED CONTROL MESH FOR CALENDER USING MATLAB: CASE STUDY AT STINFER ART IN STEEL
}

\author{
Fabiano Stingelin Cardoso ${ }^{* 1}$ \\ Federal Institute of Paraná (IFPR). Ivaiporã, Paraná, Brazil.
}

${ }^{1}$ http://orcid.org/0000-0001-5866-5230 (10)

Email: *fabiano.cardoso@ifpr.edu.br

\begin{tabular}{l} 
ARTICLE INFO \\
\hline Article History \\
Received: March $24^{\text {th }}, 2021$ \\
Accepted: April $19^{\text {th }}, 2021$ \\
Published: April $30^{\text {th }}, 2021$ \\
Keywords: \\
Process of Calendering, \\
Metallurgical Company, \\
Frequency Inverter, \\
PID - Proportional Integral \\
Derivative, \\
CLP - Programmable Logic \\
Controller.
\end{tabular}

\section{ARTICLE INFO}

Article History

Received: March 24 $4^{\text {th }}, 2021$

Accepted: April 19 ${ }^{\text {th }}, 2021$

Keywords:

Process of Calendering,

Metallurgical Company,

Frequency Inverter,

PID - Proportional Integral

CLP - Programmable Logic

Controller.

\begin{abstract}
The purpose of this article is to conceive automation and control in the process of calendering metal sheets in a calender that currently do not have these resources. The study will propose a viable solution so that the metallurgical company Stinfer Arte em Aço, which currently uses this equipment with manual operation processes, can have a control and automation solution in the calendering process. Taking into account the need to adapt other equipment that provide automation and control for the pre-existing calender and with a view to delivering a lean solution to the calender, which aggregates sensors, and actuators that control and optimize the efficiency of the process, this equipment was evaluated for the CFW-500 frequency inverter model, as it not only has the internal controller for closed loop PID - Proportional Integral Derivative, it also has special functions and inputs of a PLC - Programmable Logic Controller. In this process, in addition to the configuration to be inserted in the control interface of the frequency inverter by the user, it will require the placement and removal of the material to be formed, as the present study focuses only on automation and process control and automation of the calender.
\end{abstract}

\section{INTRODUCTION}

Due to the advancement of modern production systems, increasingly sophisticated and detailed, it is necessary to understand the mapping of the development of intelligent autonomous machines. To this end, the present work will demonstrate the modeling of a preexisting sheet roll forming machine in the company Stinfer Arte em Aço [1]. Figure 1 shows the calender for modeling the closed loop in Matlab.

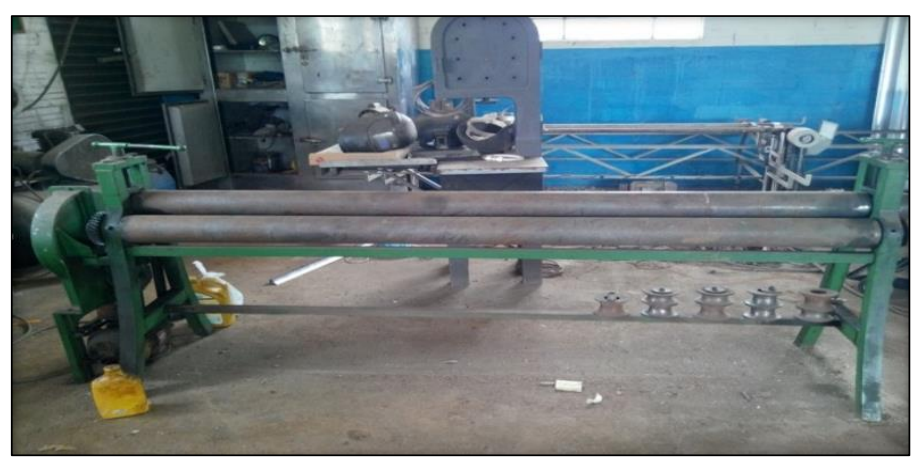

Figure 1: Sheet Metal Forming Calender. Source: Author, (2021). 
Aiming at the closed loop operation from the use of the PID controller, present in the CFW-500 frequency inverter model, they propose to use sensors for the feedback of the system, with information on 5 measurement points of the plate forming process for improvement equipment performance (calender) and reduced equipment setup time, depending on the material to conform.

Operating profiles must be generated for each raw material (sheet metal) of varying dimensions. By measuring strategic points with different controls at each modeled point of the PID controller (proportional, integral, derivative). Once the intention to generate calendering profiles is defined, it is necessary to add items due to the impossibility of feeding information to the system, which, until then, operates in open loop, with no means of eliminating possible errors in relation to the desired value. Figure 2 shows the intelligent control model for the sheet metal forming calender.

\section{THEORETICAL REFERENCE}

According to the CFW-500 Inverter model user manual [2], there are special functions included in the inverter software that, when activated, cease to assume a pre-configured constant frequency and start to apply the derivative integral proportional control factor, for compensate for any frequency readjustments in the calender motor, so this function assumes the PID regulator that is used to control the closed loop process.

This special function allows to establish a process variable as a setpoint, that is, a variable that in the applied study controls the angle of curvature of the metal sheet through a digital angle meter, goniometer, which when reaching the angle established on the HMI interface or via P525 (digital setpoint) disables the compression of the control to the system through the measurement signal generated by the sensor (goniometer), responsible for the feedback of information, which in turn makes the comparison of the measured value with the reference value, a value that is fixed In this phase of the process, the difference between values (measured and reference) determines the error, then we use the error to generate the correction signal in order to eliminate the deviation by bringing the variable to desired values, then acting on the analog input of the drive motor. hydraulic pump that exerts pressure on the roller whose function is to press the metal sheet, thus reaching the expected angle of curvature (reference value cia).

In Figure 2 the process is shown through a diagram of the PID regulating function that uses these special functions of the frequency inverter.

Basically, the procedure for putting the PID regulator into operation on the CFW-500 frequency inverter is shown in Figure 2.

1) Process - Define the type of PID action that the process requires: Whether forward or reverse. The control action must be direct $(\mathrm{P} 527=0)$ when it is necessary for the motor speed to be increased to cause the process variable to be increased. Otherwise, reverse must be selected $($ P527 $=1)$.

Examples: a) Direct: Pump driven by an inverter filling a reservoir with the PID regulating its level. In order for the level (process variable) to increase, it is necessary that the flow rate and consequently the motor speed increase. b) Reverse: Fan driven by an inverter cooling a cooling tower, with the PID controlling its temperature. When you want to increase the temperature (process variable) it is necessary to reduce the ventilation by reducing the motor speed.

2) Feedback - Measurement of the process variable: It is always via analog input AI1 and the transducer (sensor) must be used for feedback of the control variable. It is recommended to use a sensor with a full scale of at least 1.1 times the highest value of the process variable to be controlled.

Example: If it is desired to control the pressure at $20 \mathrm{bar}$, choose a sensor with a full scale of at least 22 bar. The type of signal is adjusted via P235 according to the signal from the transducer (4-20 mA, 0-20 mA or 0-10 V). The digital setpoint P234 must be adjusted according to the variation range of the feedback signal used (more details can be obtained in the description of parameters P234 to P240 of the CFW-500 frequency inverter).

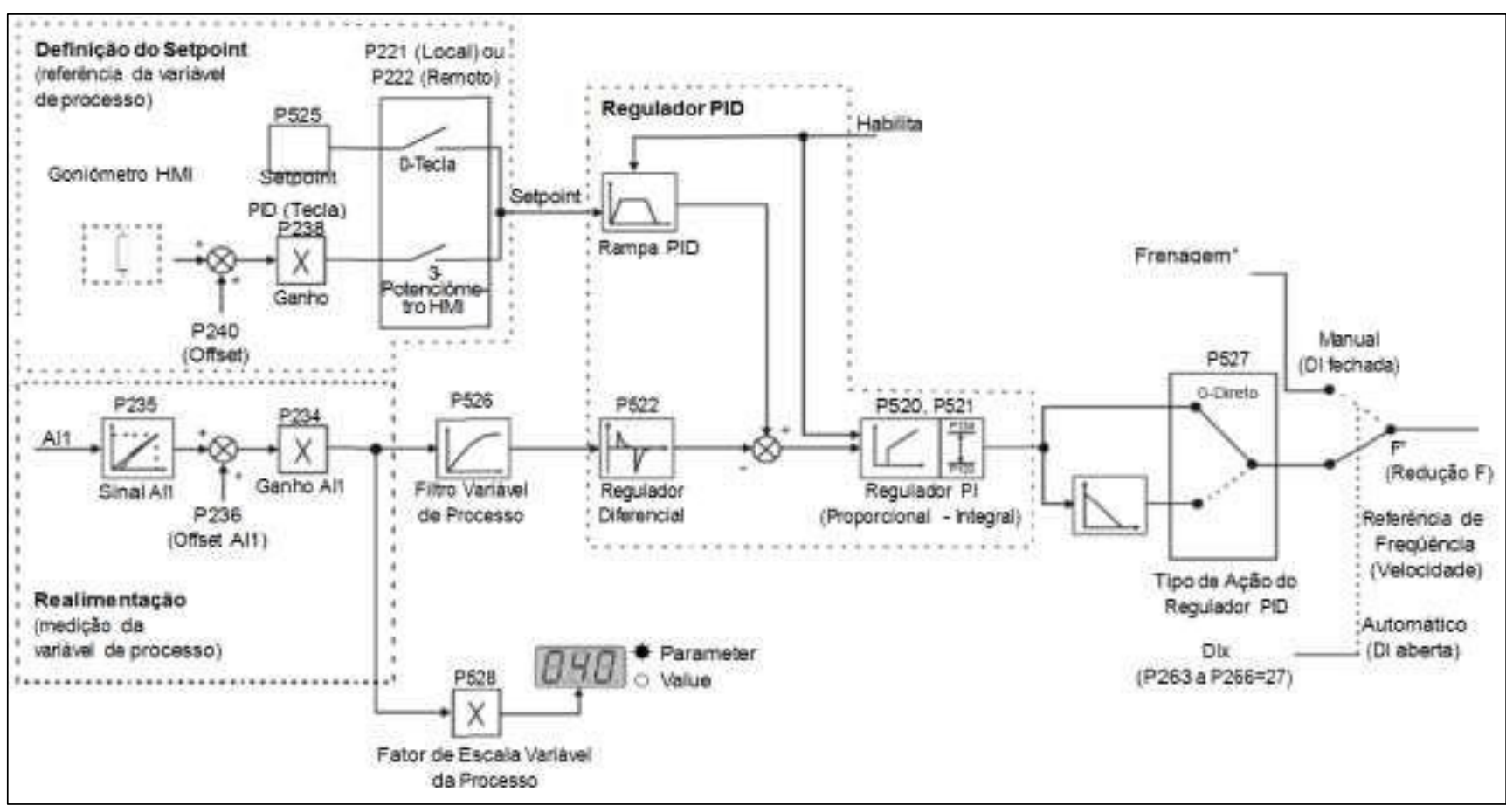

Figure 2: Inverter PID regulator CFW-500.

Source: WEG, (2021). 


\section{MATERIALS AND METHODS}

For the elaboration of this modeling, bibliographical and documentary researches were carried out on calenders, frequency inverters, electric motors, pneumatic compression pumps [3], pressure gauges, sensors. In this way, relating the need for acquisition for the calender plant the following items:

$01 \mathrm{CFW}-500$ frequency inverter;

02 electric motors;

01 hydraulic pump;

01 compression meter with analog output;

04 digital sensors.

Work routines on industrial automation machines were investigated, as well as the communication of these machines with the programmable logic controllers; it was verified with this, the possibility of making viable through the SoftPLC software for the development of the control via computer [4]. work are:

The methods and techniques that were used in making the

Deductive method: comes from the study of the general to the particular;

Qualitative research: bibliographic or documentary.

\section{RESULTS AND DISCUSSIONS}

The present study aims to model a closed loop in a calendering process that currently works in open loop. For the success of this objective, a model is fundamental, a model that must cover the largest number of stages where the performance of the variables has the greatest influence on the behavior of the process. For this purpose, the existence of the following operation model was observed, as shown in Figure 3.

Mapping the main points of the calendering process, there was a need for equipment that provides measurements at each of the following points:

- Compression adjustment (to fix the part to the calender before starting the process);

- Angulation adjustment (determines the spacing between the rollers that will determine the angle of the part to be processed by the calender);
- End of stroke control (sensor that determines the end of the plate),

- Torsion adjustment (determines the force applied to the compression process, so that the material does not exceed the limit of elastic deformation, so that its retraction stops at the expected plastic deformation point, avoiding that the slip point does not remain away from the margin);

- Speed Adjustment (determines speed variation through a frequency controller, so that, according to the force applied to the process, there is a change in speed).

For each of the measurement points raised there is a need to determine reference variables (which can be fixed or variable) in the calendering process, in order to use a reduced model in the study, to determine the calendering profile of the equipment adapted to each plate or material.

With the aim of improving performance, increasing process efficiency through closed-loop control, we arrived at the particular closed-loop model for control shown in Figure 4.

For the control of the curvature or calendering process of a plate, we determine the reference value by analyzing multiple factors. The main mechanical force applied to a body that undergoes deformation, which is studied by the variable " $\mathrm{K}$ " of Hooke's law. This law considers, in addition to the deformation force, also the retraction force of the material, that is, the elastic force of recovery to the previous state, thus the equation that applies Hooke's law foresees an additional force to compensate for the retraction of the material, the formula is obtained by:

$$
F=\mathrm{k} \cdot \mathrm{x}
$$

Where:

$\mathrm{F}$ is the intensity of the applied force (Newton),

$\mathrm{k}$ is the elastic constant $(\mathrm{N} / \mathrm{m})$,

$\mathrm{x}$ is the material deformation variable.

It is important to note that although the equation is usually studied by the extension of a spring, it can also be applied to compression, flexion, torsion and others.

For the calendering process, the force $\mathrm{F}$ is directly proportional to the angle that will be applied to the final piece, and, to reach the determined angle, the process usually goes through several cycles with this force being applied gradually throughout the entire process.

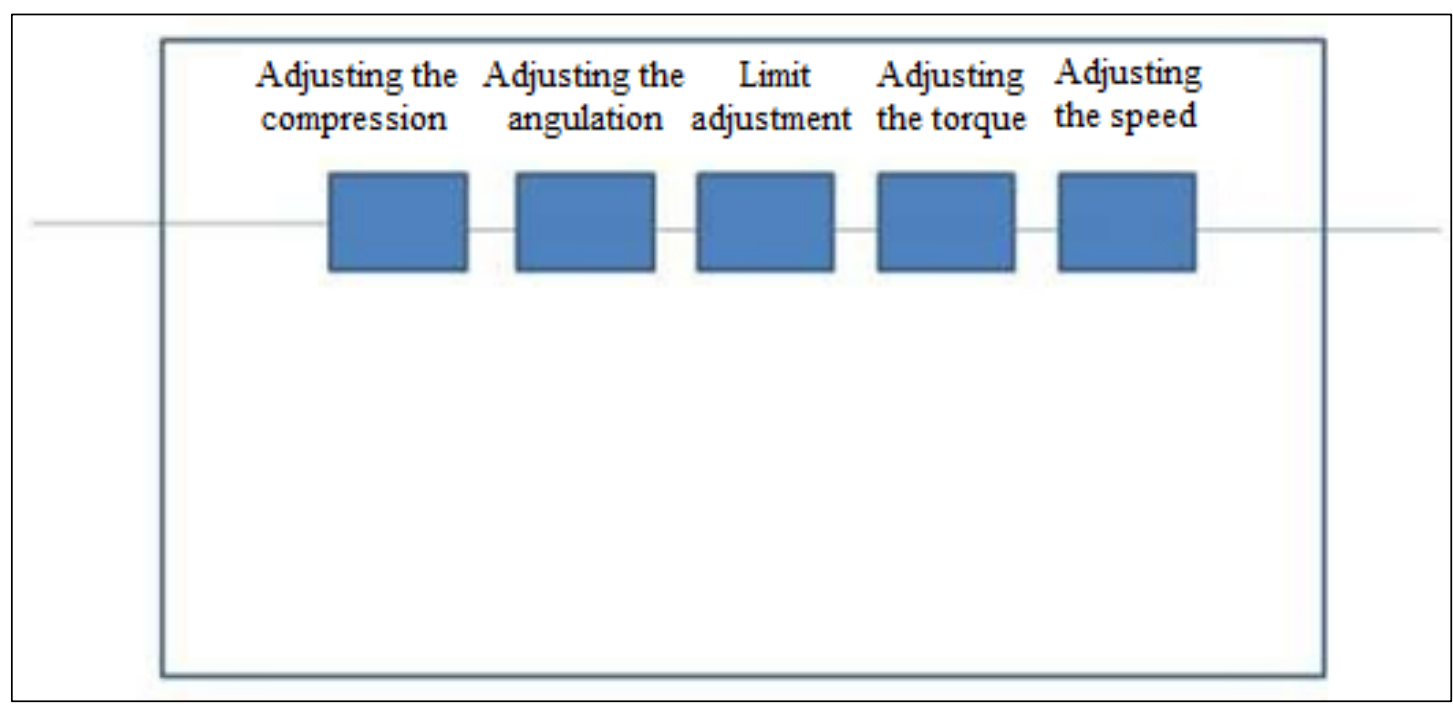

Figure 3: Current process.

Source: Author, (2021). 


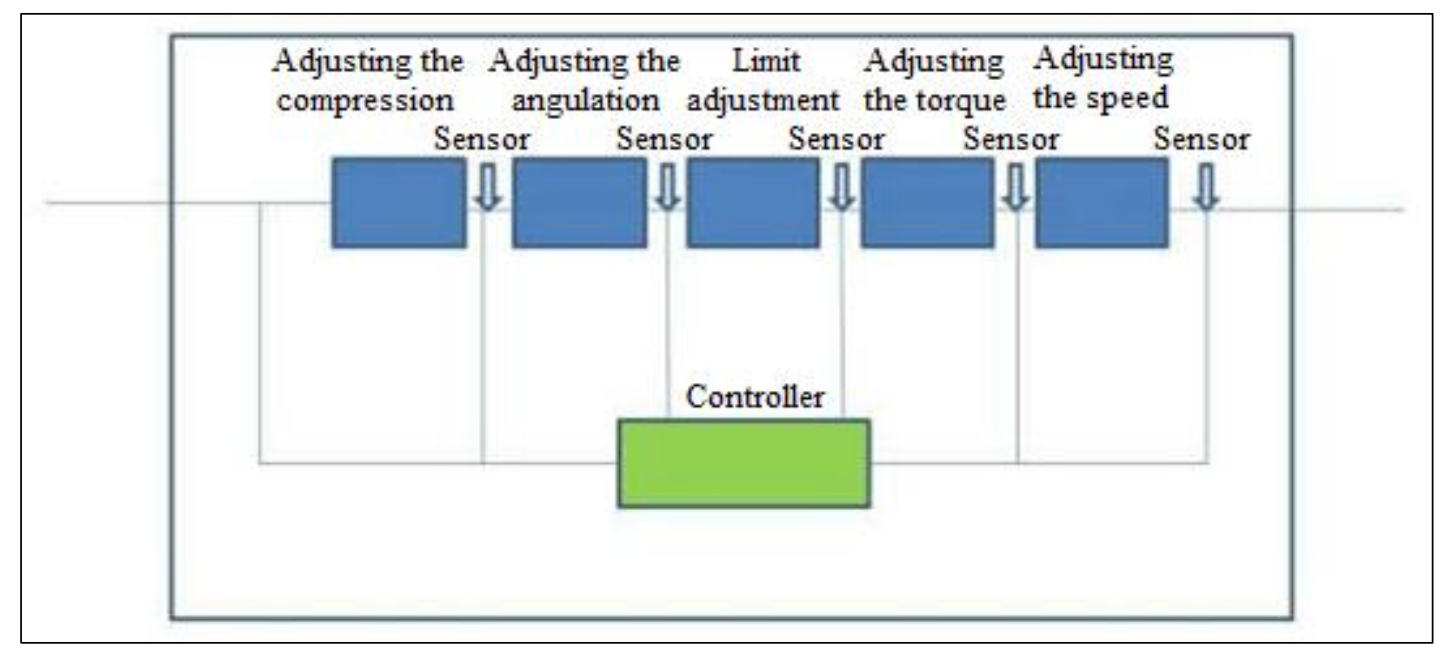

Figure 4: Future process.

Source: Author, (2021).

These are factors that influence the applied force to reach the reference angle, thickness and material; quantities that are variable due to the difference in parts to be manufactured and their variation directly influence the number of cycles to complete the process.

Speed is also among the indispensable variants that need to be monitored for feedback and subsequent performance in the closed-loop calendering process, since the electric motor is responsible for the operation of the machine, transforming electrical energy into mechanical force. Also, limitations regarding the applied torque must be raised, an excessively high torque may be necessary to form the desired angle in the part, however, it can be above the capacity of the electric motor, and it is essential to control this variable.

The use of closed loop to the process occurs by inserting a control to match the reference values of the measured values, for this purpose the PID controller, derivative integral proportional controller, or simply PID was used; it is a process control technique that unites the derivative, integral and proportional actions, thus causing the error signal to be minimized by the proportional action, zeroed by the integral action and obtained with a speed anticipated by the derivative action. Defined mathematically by the following formula:

$$
u(t)=K_{p} e(t)+K_{i} \int_{0}^{t} e(r) d r+K_{d} \frac{d e(t)}{d t}
$$

Where:

$\mathrm{K}_{\mathrm{p}}$ is the Proportional Gain,

$\mathrm{K}_{\mathrm{i}}$ is the Integral Gain,

$\mathrm{K}_{\mathrm{d}}$ is the Derivative Gain,

e it's the Error,

$\mathrm{t}$ is Time,

$r$ is the Integration Time.

\section{IV.1 PROPORTIONAL ACTION}

Proportional control acts by applying a signal called proportional gain to the actuator that will cause the actuator to act in the inverse proportion to the error.

The error is nothing more than the difference between the reference value and the measured value, therefore, the greater the error the greater the gain to compensate for this error, however the error will never reach a null value using only the proportional control.

Applying the reference value to the process will be the angle of the plate at the end of the process, this angle is obtained by the force applied to the plate as mentioned in Hooke's law, for the creation of work profiles it is necessary that the first cycle of the process has a applied experimental force, after the first cycle with a force $\mathrm{x}$ applied, the digital goniometer will measure the angle obtained $\mathrm{z}$, feeding this information to the PID controller, where the difference between the angle obtained $\mathrm{z}$ and the reference that we will call y will be made, then :

$$
\text { Error }=\mathrm{z}-\mathrm{y}
$$

As the error value has been determined, the controller will apply a signal contrary to the error, called a proportional gain, to bring this variable closer to the reference value, highlighting that by proportional error control it will not reach a null value $(=0)$. For example, for the reference angle $\mathrm{Az}$ of 400 a force of $100 \mathrm{~N}$ is applied, and in the first cycle it is measured by the goniometer, the angle obtained was 250 .

Through the Proportional control formula:

It has if:

$$
P_{\text {exit }}=K_{p} e(t)
$$

$$
\begin{aligned}
& \mathrm{Az}=40 ; \text { Error }=15 ; P_{\text {exit }}=15 K_{p} \\
& \mathrm{Az}=35 ; \text { Error }=10 ; P_{\text {exit }}=10 K_{p} \\
& \mathrm{Az}=30 ; \text { Error }=5 ; P_{\text {exit }}=5 \mathrm{~K}_{\mathrm{p}} \\
& \mathrm{Az}=30 ; \text { Error }=5 ; P_{\text {exit }}=5 \mathrm{~K}_{\mathrm{p}}
\end{aligned}
$$

Since $K_{p}$ is a proportionality constant, at a certain point it will no longer influence the error, an error that will be compensated for by full control.

\section{IV.1I INTEGRAL ACTION}

Proportional The integral action makes the sum of the errors over time, the error is represented numerically by an area that exists between the reference value and the area of the last measurement, the value of the error is compensated for by the constant integrality or integral gain $K_{i}, K_{i}$ current in the compensation at regular intervals, therefore, even if the error has a very low value, the integral response increases, the effect is to drive the error to a null value. 
For this process uses the formula:

$$
I_{\text {exit }}=K_{i} \int_{0}^{t} e(r) d r
$$

Analyzing the formula we realize that the error is integrated in relation to the time and the $K_{i}$, which in turn will make the compensation in each instant of time, no matter how small the error, there will always be a $K_{i}$ gain compensation, unless the error is null (Error $=0)$, for error values very close to zero (0), the system displays a damped response, then the derivative control acts.

Applying the reference value to the process being the angle, and this value being changed by increasing the applied force, we will arrive at the angle value, applying the integral to the smallest error reached by the proportional gain, in the range of 0 at, taking the error to the zero which is the same thing as the process reaching the reference value. In the case of the example, the angle value of 250. As already mentioned, in the phase of an error very close to zero, the integral gain will cause the system response to be over-damped, so the process may take a long time until it reaches zero error $(0)$.

\section{IV.1II DERIVATIVE ACTION}

The Derivative Control is the simplest, it is responsible for reducing the accommodation time making the control system obtain the value more quickly, in addition, it reduces the overshoot time having a direct effect on the climb and also on the error of permanent regime.

\section{IV.1V PID ACTION}

According to the writer Katsuhiko Ogata, [5] renowned author of the book Modern Control Engineering, we have the function of transfer between the displacement $\mathrm{z}, \mathrm{y}$ described by the following equation:

$$
\frac{Z(s)}{Y(s)}=\frac{1}{M s^{2}+b s+K}
$$

Where we have:

$\mathrm{M}=98.67 \mathrm{~kg}$

$\mathrm{b}=10 \mathrm{~N} . \mathrm{s} / \mathrm{m}$

$\mathrm{K}=100 \mathrm{~N} / \mathrm{m}$

$\mathrm{F}(\mathrm{s})=1$

The transfer function to the closed loop of the system with PID control is as follows:

$$
\frac{Z(s)}{Y(s)}=\frac{K_{d s}{ }^{2}+K_{p s}+K_{i}}{s^{2}+\left(10+K_{d}\right) s^{2}+\left(100+K_{p}\right) s+K_{i}}
$$

After several trial and error executions, the gains $K_{p}=$ $950, K_{i}=1500$ and $K_{d}=95$, resulted in a response closer to the desired one, the following commands were executed in MATLAB:

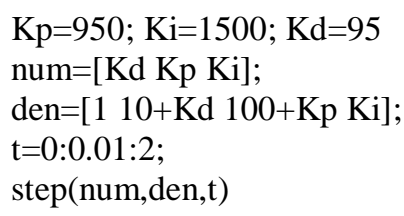

That after the simulation in MATLAB [6] the following graphs were obtained:

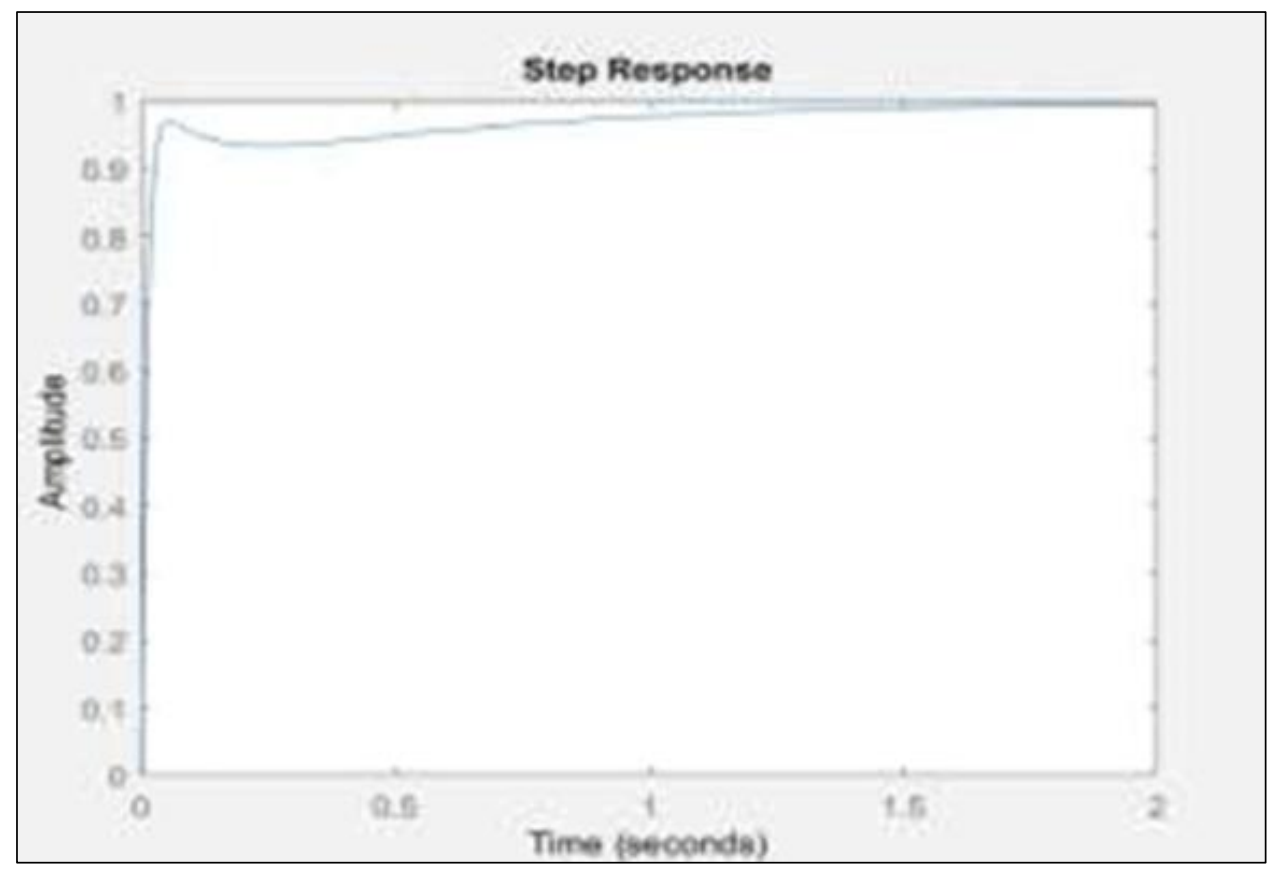

Figure 5: Amplitude of the Transfer Function Source: Author, (2021). 


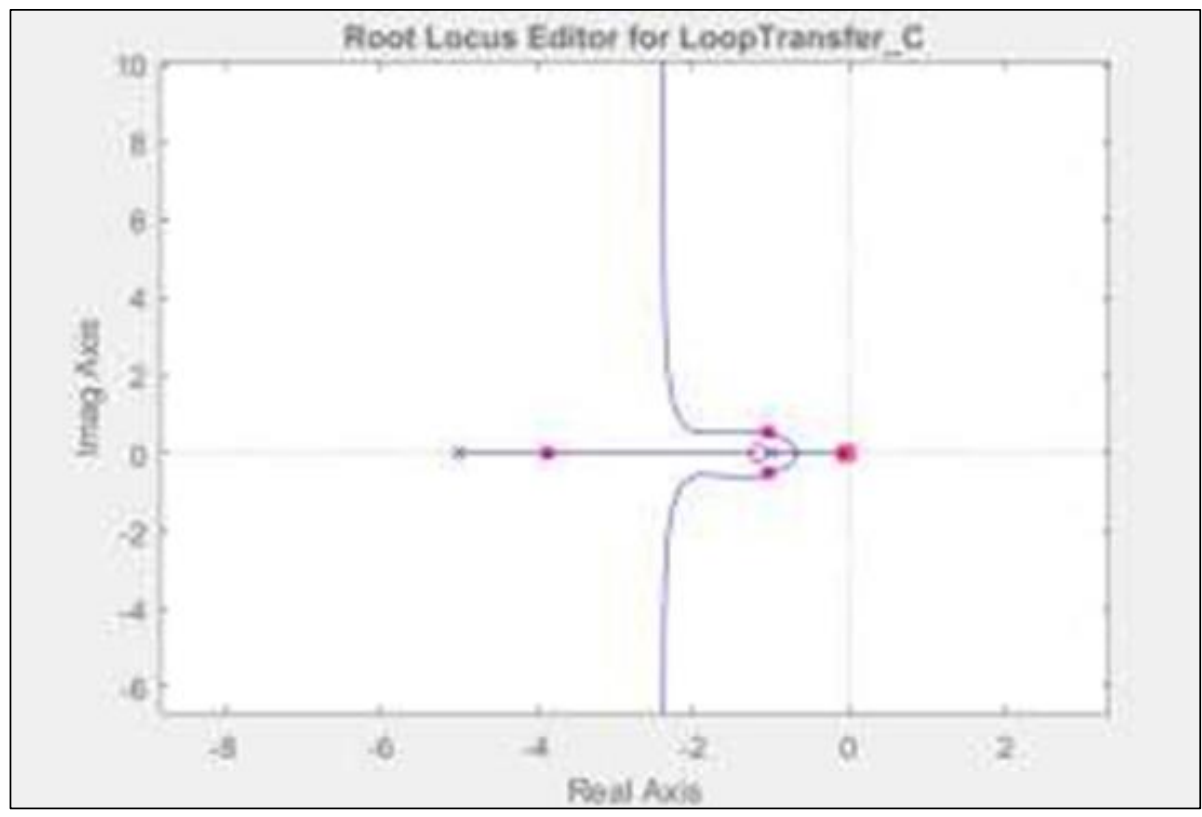

Figure 6: Pole Orientation for Gain in Transfer Function

Source: Author, (2021)

\section{CONCLUSIONS}

The work developed based on a practical model allows to identify control and automation design points effectively, since, when evaluating an open loop, it is possible to identify points to be implemented in closed loop modeling.

It was observed a wide possibility of applications of frequency inverters, in view of the multiple models found in the market, with their functionalities differentiated according to the application. Currently, the company WEG takes the market leadership in this segment of the Brazilian market.

The company Stinfer, evaluated in the implementation of the control, will certainly obtain efficiency in its production processes, once the standardization in the conformation of the metal sheets will be reached and it will be detached from manual controls until then used.

Thus, in this study, it is concluded that the application of the addition of the PID controller (Proportional, Integral and Derivative) allows to improve the rise time and at the same time makes it possible to be cautious about the system presenting an overshoot or very high signal, and through of adjustments in the control variables it is possible to minimize the losses and maximize the gains.

\section{AUTHOR'S CONTRIBUTION}

Conceptualization: Fabiano Stingelin Cardoso.

Methodology: Fabiano Stingelin Cardoso.

Investigation: Fabiano Stingelin Cardoso.

Discussion of results: Fabiano Stingelin Cardoso.

Writing - Original Draft: Fabiano Stingelin Cardoso.

Writing - Review and Editing: Fabiano Stingelin Cardoso.

Resources: Fabiano Stingelin Cardoso.

Supervision: Fabiano Stingelin Cardoso.

Approval of the final text: Fabiano Stingelin Cardoso.

\section{REFERENCES}

[1] Stingelin, Antônio; Stingelin, Fernando. Nascemos de um sonho e determinação. Para hoje sermos especializados em projetos de alto padrão e qualidade.. Disponível em < https://www.facebook.com/grupostinfer/> Acesso em: 15 Jan. 2021.
[2] WEG. Manual do Inversor de Frequência CFW-500. Disponível em <http://www.weg.net/br/Media-Center/Central-de-Downloads/Resultado-daBusca?keyword=CFW-500\&x=0\&y=0>. Acesso em: 24 Fev. 2021.

[3] BOSCH. Unidade Hidráulica Compacta. Disponível em <https://www.boschrexroth.com/pt/br/produtos/grupos-de-produtos/hidraulicaindustrial/topicos/unidades-hidraulicas-abdt/index >. Acesso em: 24 Fev. 2021.

[4] Asksistemas. SoftPLC - funcionalidades de CLP incorporadas. Disponível em $<$ http://asksistemas.com.br/inversores-de-frequencia/>. Acesso em: $06 \mathrm{Fev}$. 2021.

[5] Ogata, Katsuhiko. Engenharia de Controle Moderno. Universidade de Minnesota, Rio de Janeiro: Editora Prentice/Hall do Brasil Ltda., 1982.

[6] Gilat, Amos. MATLAB Com Aplicações em Engenharia. 2.ed., Porto Alegre: Editora Bookman, 2006. 